\title{
Higher education require adaptation of students study abroad programs
}

\author{
Vojtech Ferencz ${ }^{1}$, Daniela Hrehováa ${ }^{2,}$, Andrea Seňová ${ }^{3}$ \\ ${ }^{1}$ Technical university in Kosice, Letná 9, 04000 Kosice, Slovakia \\ ${ }^{2}$ Technical university in Kosice, Vysokoškolská 4, 04000 Kosice, Slovakia \\ ${ }^{3}$ Technical university in Kosice, Park Komenského 19, 04384 Kosice, Slovakia
}

\begin{abstract}
Globalization includes transnational political, economic and cultural ideologies and values. Globalization has a significant impact on education as new positions can enter higher education and study abroad. The influx of foreign students in Slovakia increased significantly. Therefore, successful interaction with the school environment and constant adaptation to the country are crucial for all students. However, many students face challenges when they attend higher education outside their home countries. The article shows that various investigators have carried out a large number of studies on the factors that affect students' ability to adapt to different global challenges. The article provides some results of students' adaptation effects during the first year of the Technical University in Košice. in the Daily Life section, we recorded statistically significant results between groups (Ukrainian students and other foreign students). Globalization includes transnational political, economic and cultural ideologies and values. The findings of the research questionnaire have important meaning for educators to help students in their efforts to succeed in a period of globalization and in adaptation in real educational practice. The university must be prepared to meet students not only academically, but also socially and culturally.
\end{abstract}

\section{Introduction}

Universities are unique kinds of global institutions. When wisely designed, governed and financed, they are unique entities in our democracy and in our global society. Internationalization is seen as something higher education institutions do while globalization is something that is happening to them. We see international students moving freely around the world, contributing to globalization. Internationalization of higher education allows them to cross borders. Universities must focus on the individual. They must provide unique environments that prepare students to be "master thinkers" able to grasp a wide array of skills and comprise the most adaptable. The innovation and adaptation are needed now more than ever before in our international higher education infrastructure.

* Corresponding author: daniela.hrehova@tuke.sk 


\section{Theoretical Background}

A literature review discovered important knowledge gaps in the findings on school. First, most previous research focuses on young children's adaptation to schools (for example [12, 14] or on high school students [18], while only a few focus on college students' adaptation $[11,13]$. Successful transition and adaptation to university might benefit students in multiple ways, such as providing them with a strong academic basis so that they will be prepared for college, as well as enhancing their abilities to monitor and regulate themselves so that they can avoid problematic behaviors. Given the recent demand for internationalization and globalization of our world, and cross-border student mobility around the world has ensued [2]; the inflow of international students in the United States has increased significantly. International students cannot escape the cultural shock and change they experience during their studies in the US. These changes occur across physical, biological, cultural, social relationship, and psychological (behavior and mental health status) domains [3]. However, many international students face challenges as they pursue higher education outside of their home countries [15]. They face obstacles, such as different food, unfamiliar living circumstances, financial problems, balancing work, studying schedules, learning styles, or any difficulties related to language, culture, and personal barriers. A series of transitional difficulties can be from daily life to cultural adaption [21]. If American colleges are going to embrace international students on their campuses, these issues should be addressed and accommodated. Successful freshman adaptation to university life, as gauged by a number of studies [4, 7] indicate that the transition from environment to university life is full of stress for first year university students. These students are exposed to both interpersonal, academic and personal obstacles. Author Farris [6] states that adaptation difficulties refer to "the problems which students might face with getti ng involved, maki ng friends, being away from home, as well as many others". A number of researchers (example [9, 20]. Authors Park and Kim [16] suggest that academic adaptation/adjustment and social integration at an early stage and social integration into new study environments are an important factors in achieving successful adaptation. Adaptation is considered one of the most important capacities of human behavior, and it is also a factor in human motivation and in satisfying human needs (example [1]). Pukalos at al. [17] also defined adaptation as human beings' active modification of their own behaviors, so as to adjust themselves to meet the requirements of a new environment.

\section{Research}

As a part of Quality Objectives of Technical University in Košice for 2018, its Department of Social Sciences conducted research on adaptation of international students to the life and studies at the Technical University in Košice. As a part of Quality Objectives of Technical University in Košice (TUKE) for 2018, its Department of Social Sciences conducted research on adaptation of international students to the life and studies at the Technical University in Košice.

\subsection{Purpose, research methodology and characteristics of respondents}

The research was condemned in all 6 faculties of TUKE focusing on the first-year mobility students who had already gone through the initial phase (stage) of studies at the university and to some extent they had already adapted to the new requirements. It was the period within which they were faced with increased demands concerning adaptation to the newlyarisen situation that was closely associated with a severe change of environment, travelling to foreign country to study abroad. Based on the findings, it will be possible to propose 
alternative solutions to identified shortcomings and thus to help to streamline the adaptation process of international students.

The research sample consisted of 241 foreign students. The largest group consisted of 170 Ukrainian students. The next largest group was made of 51 students from India. The totals of 18 students were from different countries.

The main objective was to identify the difficulties which foreign students encounter during their stay in Slovakia while studying at TUKE.

The questionnaire used for research purposes contained 78 items which were divided into following several areas:

- everyday life,

- studies in educational contexts,

- studies in social context,

- studies in cultural context,

- how to access information about TUKE.

Items named the information and skills that were considered most important for the successful adaptation of foreign students during their university studies.

In this article, we study the everyday life of international students who were responding to our questions on a scale from 1 to 5 while choosing 1 of the following options 1 - not at all, 2 - to a small extent, 3 - I sometimes experience, 4 - I often experience, 5 - I very often experience difficulties. Students answered twenty questions that were related to the area in question. The exact wording of these questions reflected the need to be looking for a solution to this issue « with someone» and we also asked participants to share the specific idea on how to offer aid and assistance. Thus, the answers we were given were qualitative.

The obtained data were evaluated by the statistical package (SPSS). In particular, we investigated and compared the responses of Ukrainian and other students (the English speaking ones). The results were processed by statistical procedures, the t-test to detect differences between groups.

\subsection{Results}

For the purposes of this article, we have recorded statistically significant results in the section «everyday life»:

Concerning their language of communication, the arithmetic average of students from Ukraine (hereinafter referred to as $\mathrm{AM}$ ) was 2.22, with a standard deviation (hereinafter referred to as SD of 0.96), the AM for Indian students was 3.33, with a standard deviation of 1.11; which is a statistically significant difference resulting from the different cultural languages of Indian students, which impede their ability to communicate effectively.

The statistically significant results among the groups are related to the section "Life at the dormitory" (AM for Ukrainian students is 1.85 , with $1.05 \mathrm{SD}$; For other students AM is 2.65 and SD 1.41). Findings show that living in the dormitory of other foreign students according to the different set rules constitutes a problem. This is related to another finding concerning the acceptance by and coexistence with one's roommates in the dormitory. The Ukrainian students' $\mathrm{AM}$ accounts for 1.75 with SD of 0.98 ; while for other students AM is 2.40 and $\mathrm{SD}$ equals 1.30. This makes us acknowledge the presence of cultural differences arising from differing traditions, and in comparison to their previous lifestyle, it constitutes a change, which interferes with achieving the level of „smooth" coexistence. Students also reported statistically significant results in communication with the accommodation department. For Ukrainian students, AM equals 1.72, SD is 0.87; while for other students, $\mathrm{AM}$ is as much as 2.51 with $1.27 \mathrm{SD}$.

It turned out that for other foreign students even doing shopping is an issue. On the other hand, Ukrainian students' AM in this sphere is 1.27 , with SD of 0.73 , thus no major 
problems were discovered. Other foreign students' AM reaches the value of 2.51, and SD the value of 1,47 ; thus, for non-Slavic students doing shopping means a problem. Significant differences in daily routine were noted in the sphere of obtaining everyday services (haircut, cosmetics), with Ukrainian students we measured the AM of 1.79 and the $\mathrm{SD}$ of 0.99 . In comparison to that, the AA of other foreign students constitutes a value of 2.58 and $\mathrm{SD}$ equals 1.24 . This area therefore also accounts for a critical sphere.

\subsection{Discussion}

The academic, social and emotional adjustment is influenced by a number of factors. As freshmen arrive at university with different personal, social, cultural and linguistic backgrounds, and characteristics, the factors that affect the adjustment process necessarily vary from one student to another. However, gender, self-esteem, and student expectation of university life have been identified as important factors influencing successful adaptation. Coming to a new country, international students are faced with the reality of needing to find places to live and finding banks to deposit and withdraw money and transportation by finding buses or buying cars to move around and applying for credits cards. Surviving in a new community is the first lesson they have to deal with, and they need to have a support system when they newly arrive. Many studies [5, 19] explored the challenges and hurdles experienced by international students attending institutions of higher education in the US. These difficulties include, but are not limited to, language difficulties, difficulties adjusting to the academic culture, misunderstanding, and complications in communication with faculty and peers; stress, anxiety, feeling of isolation, social experiences, culture shock, financial hardships, lack of appropriate accommodation, isolation and loneliness, and any adaption in their daily life. Language is considered one of the greatest academic issues hindering smooth adjustment for international students [8]. Toussaint and Crowson [10] examined 188 American students' negative attitudes toward international students. The international students pose threats to their economic, education, physical well-being, beliefs, values, and their social status from anti-immigrant prejudice.

Theoretical background and findings (both different and corresponding):

(1) show that living in a new culture means many changes in students' lives including separation from family and friends, meeting new friends and developing networks, learning new social customs and behaviours, experiencing a different climate and different types of food;

(2) They also give a range of incentives to all pedagogical and non-pedagogical staff at the university as to reflect on how to improve adaptation in a broader context.

First of all, it is necessary to establish the so called "Adaptation University Programme", which would be based on the concept of creative-humanistic education and learning process. This implies improving the various organisational forms of teaching, motivating students, developing their desire for education, self-realization, selfimprovement and self-reflection in the process of formal and non-formal learning. However, the pursuit of a successful adaptation cannot be, of course, just a matter of school, but it must be a personal matter for every student. The adaptation of new students to the high school conditions should be run as a planned process that is continuously monitored and evaluated. Without students making some efforts, they cannot benefit from the work of their pedagogical and non-pedagogical staff and adaptation becomes rather a long process. 


\section{Conclusion}

Colleges and universities face growing pressure from state legislatures, the federal government, and the broader public, including students themselves, to become more accountable for improving adaptation, among other measures.

We are inclined to believe that the achievement of general improvement in student's adaptation will require considerable effort, resources and system approaches of individual departments, faculties, university management as well as pedagogical proficiency of college professors. In many ways, the extent of progress will depend on whether and to what extent educational institutions will give adaptation issues more attention and weight than they have so far.

The article is supported by the project MŠVVaŠ SR KEGA č. 049TUKE-4/2019 Foreign Students' Education with an Emphasis on Creating Key Competences in the Context of Building a Working Career and the Inclusion into the Labor Market in Slovakia.

\section{References}

1. S. O. AlZboon, Social adaptation and its relationship to achievement motivation among high school student in Jordan. Int. Educ. Stud. 6, 63-69 (2013)

2. P. G. Altbach, J. Knight, The internationalization of higher education: motivations and realities. J. of Studies in Internat. Educ. 11, 3-4, 290-305 (2007)

3. J. W. Berry, U. Kim, T. Minde, and D. Mok, Comparative Studies of acculturative stress (Canada). International Migration Review 21, 3, 491-511 (1987)

4. H. Elias, R. Mahyuddin, R., J. Uli, Adjustment amongst first year students in a Malaysian university. European Journal of Social Sciences 8, 3 (2009)

5. E. A. Erichsen, D. U. Bolliger, Educational Technology Research and Development 59, 3, 494-505 (2011)

6. A. Farris, The freshmen adjustment process: Commuter life versus residence life. Unpublished master's thesis, California State University, Sacramento (2010)

7. L. Friedlander, G., Reid, N. Shupak, N., R. Cribbie, Social support, self-esteem, and stress as predictors of adjustment to university among first year undergraduates. Journal of College Student Development 48, 3, 259-274 (2007)

8. F. J. Galloway, J. R. Jenkins, The adjustment problems faced by international students in the United States: a comparison of international students and administrative perceptions at two private, religiously affiliated universities. NASPA Journal 42, 2, 175-187 (2005)

9. J. Grayson, The consequences of early adjustment to university. Higher Education 46, 411-429 (2003)

10. G. C. Charles-Toussaint, H. M. Crowson, Prejudice against international students: the role of threat perceptions and authoritarian dispositions in U.S. students. The Journal of Psych.: Interdiscipl. and Applied 144, 5, 413-428 (2010)

11. M.M. Chemers, L. Hu, B.F. Garcia, Academic self-efficacy and first-year college student performance and adjustment. J. Educ. Psychol. 93, 55-64 (2001)

12. S.A. Chi, S. Kim, N.H. Kim, S. A study of school adjustment related variables of young children. Afr. J. Educ. 38 1-9 (2018)

13. C. Lee, Y.T. Sung, Y. Zhou, S. Lee, The relationships between the seriousness of leisure activities, social support and school adaptation among Asian international students in the US. Leisure Stud. 37, 197- 210 (2018) 
14. K. Margetts, Early transition and adjustment and children's adjustment after six years of schooling. Eur. Early Child. Educ. Res. J. 17, 309-324 (2009)

15. O. Ozturgut, C. Murphy, Literature vs. practice: challenges for international students in the U.S International Journal of Teaching and Learning in Higher Education 22, 3, 374-385 (2009)

16. J.S. Park, T.H. Kim, Do types of organizational culture matter in nurse job satisfaction and turnover intention? Leadership in Health Services 22, 1, 20-38 (2009)

17. E.D. Pulakos, S. Arad, M.A. Donovan, K.E. Plamondon, Adaptability in the workplace: development of a taxonomy of adaptive performance $J$. Appl. Psychol. 85, 612-624 (2000)

18. C.H. Ripple, S.S. Luthar, J. Academic risk among inner-city adolescents: the role of personal attributes. School Psychol. 38, 277-298 (2000)

19. J. Russell, D. Rosenthal, G. Thomson, The international student experience: three styles of adaptation, Higher Education 60, 2, 235-249 (2010)

20. S. Severiens, R. Wolff, A comparison of ethnic minority and majority students: social and academic integration, and quality of learning, Studies in Higher Education 33, 3, 253-266 (2008)

21. E. Yoon, T.A.A. Portman, Critical issues of literature on counseling international students, J. of Multicultural Counseling and Develop 32, 1, 33-44 (2004) 